\title{
Energia de fontes renováveis na matriz energética brasileira: uma revisão sobre o panorama atual e perspectivas futuras
}

\section{Rachel Leser Burock Chamarelli Teixeira e Wanderson Amaral da Silva*}

Centro Federal de Educação Tecnológica Celso Suckow da Fonseca. Coordenação de Licenciatura em Física. Campus Petrópolis. Rua do Imperador, 971. Centro. Petrópolis-RJ, Brasil (CEP 25620-003).

Resumo. As crises energética e ambiental impulsionaram a busca por fontes renováveis de energia ao redor do mundo nos últimos anos. No entanto, a matriz energética mundial permanece com alta concentração de combustíveis fósseis, que são poluentes e possuem preços sujeitos a instabilidades. Sendo assim, por meio de pesquisa bibliográfica, este trabalho consiste em discutir aspectos econômicos e socioambientais sobre o panorama atual e perspectivas das fontes renováveis de energia na matriz energética brasileira. Neste artigo serão tratadas as fontes de energia: solar e eólica, que têm crescido em uma taxa acelerada mundialmente e no Brasil a situação é semelhante; a hidráulica que é muito relevante no contexto nacional, porém nem todos os países dispõem deste recurso; a biomassa, que tem como principais características o aproveitamento de subprodutos e a geração de combustíveis para veículos; e a marítima que possui um grande potencial devido ao extenso litoral nacional. As fontes de energia que terão maior crescimento de implantação a nível nacional serão a térmica que, apesar de ser não renovável, complementa a matriz energética e fornece maior garantia em momentos de pico de uso de energia, a eólica e solar por serem fontes mais limpas e possuírem bom custo-benefício. A hidráulica e biomassa terão seu crescimento menor nos próximos anos, mas já possuem alta participação na matriz energética. Já com relação à energia marítima, existem diversos projetos em estudo devido à extensa área costeira nacional que pode ser explorada. Portanto, o Brasil possui grande capacidade de geração de energia através de todas as fontes citadas e se consolidar como um dos países com matriz energética predominantemente limpa.

Palavras-chave: Energia renovável; Meio ambiente; Matriz energética brasileira.

Abstract. Renewable energy in the Brazilian energy matrix: A review of the current scenario and future perspectives. The energy and environmental crises have driven the search for renewable energy sources around the world in recent years.

Recebido

05/05/2021

Aceito

01/12/2021

Disponível on line

09/12/2021

Publicado

31/12/2021

Acesso aberto

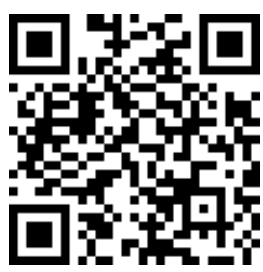

ORCID

(D) 0000-0003-1649-7640 Rachel Leser Burock Chamarelli Teixeira

(D) 0000-0002-8738-6617 Wanderson Amaral da Silva

ISSN 2359-1412/RBGAS-2021-0043/2021/8/20/16/1515

Rev. Bras. Gest. Amb. Sustent.

http://revista.ecogestaobrasil.net 
However, the world energy matrix remains highly concentrated on fossil fuels, which are pollutants and have prices subject to instability. Therefore, by means of bibliographical research, this work consists of discussing economical and socio-environmental aspects about the current scenario and perspectives of renewable energy sources in the Brazilian energy matrix. This article will address the following energy sources, solar and wind, which have been growing at an accelerated rate worldwide and in Brazil the situation is similar; hydroelectric power, which is very relevant in the national context, but not all countries have this resource; biomass, whose main characteristics are the use of by-products and the generation of fuels for vehicles; and marine energy, which has a great potential due to the extensive national coastline. The energy sources that will have the largest growth of implementation at a national level will be the thermal source, which, despite being non-renewable, complements the energy matrix and provides greater assurance at times of peak energy use, wind and solar because they are cleaner sources and have a good cost-benefit. Hydropower and biomass will have their growth slower in the coming years, but they already have a high participation in the energy matrix. As for the marine energy, there are several projects under study due to the extensive national coastal area that can be explored. Therefore, Brazil has a great capacity to generate energy through all the sources mentioned and consolidate itself as one of the countries with a predominantly clean energy matrix.

Keywords: Renewable energy; Environment; Brazilian energy matrix.

\section{Introdução}

O aumento da demanda por energia no Brasil vem crescendo ao longo dos anos e, com o surgimento de novas tecnologias para obter energia de diversas fontes, o planejamento tornou-se essencial para o desenvolvimento da economia. Ao passar dos anos foi perceptível notar que as fontes não renováveis estavam menos disponíveis e com baixos custos de extração. A alta dependência de combustíveis de origem fóssil acarretou em crises, como a do petróleo que ocorreu em 1973. Esta ocorreu quando houve escassez deste produto, ocasionando o aumento no valor do petróleo em $400 \%$, provocando uma desestabilização na economia global (Bermann, 2008; Nascimento et al., 2012; EPE, 2019).

Outro fator preocupante em relação aos combustíveis fósseis refere-se à crise ambiental que este vem causando através do aumento da concentração dos gases do efeito estufa e poluição direta do ar por diversas substâncias oriundas da combustão. Estudos apontam que a temperatura média terrestre aumentou $0,7^{\circ} \mathrm{C}$ no último século e poderá aumentar de $2{ }^{\circ} \mathrm{C}$ a $4{ }^{\circ} \mathrm{C}$ na média dos próximos anos (Correa-Macana e Comim, 2012; IPCC, 2013), podendo causar danos irreversíveis.

Derivado da preocupação política e mundial acerca da crise já vivida, foi necessário rever as políticas energéticas, as quais se pautam no emprego de combustíveis fósseis, que é um componente basal para a matriz energética mundial. Sendo assim, grandes esforços estão sendo empregados na geração de energia por meio de fontes alternativas, rentáveis 
e inesgotáveis para suprimir a escassez que já era pertinente neste período de fontes de combustíveis fósseis (Nascimento et al., 2012).

Ao iniciar o estudo sobre novas fontes geradoras de energia, é necessário analisar pré-requisitos para que houvesse uma produção de energia compatível ou superior a anteriormente utilizada. Diante deste cenário, na implantação de novos projetos de obtenção de energia, é preciso analisar diversos fatores, nos quais os principais são: promover a produção de energia que seja conciliável com as demandas do crescimento econômico; ocorrer de uma forma sustentável, de modo que aconteça o aproveitamento de recursos disponíveis no meio ambiente, provocando o menor impacto sobre o meio e com custos de produção ajustados para que não haja prejuízo ao usuário diante da realidade econômica vivida. Mediante a estes fatores, é incontestável a utilização dos recursos naturais que a Terra dispõe, como água, ar, sol e derivados vegetais. Obtêm-se assim o emprego das fontes alternativas e renováveis como modo de ajustar a desproporção de oferta e demanda, aumentando a capacidade de investimento dos setores de otimização da energia elétrica (Bermann, 2008; Vichi e Mansor, 2009).

E por meio deste contexto, as fontes renováveis de energia transmutam de fontes esgotáveis e poluentes em fontes inesgotáveis e pouco poluentes, sendo cada dia mais difundidas no mundo e possuindo cada vez mais investimentos em pesquisa e aprimoramento nas tecnologias empregadas (Nascimento et al., 2012).

Diante deste contexto, o objetivo deste trabalho é explorar as principais fontes renováveis de energia existentes no Brasil, de modo que demonstre sua efetividade, funcionamento, rentabilidade, impactos ambientais, sociais e econômicos, assim como o panorama atual e perspectivas futuras. $O$ trabalho foi desenvolvido sobre os preceitos do estudo exploratório por meio de uma pesquisa bibliográfica sobre as fontes de energia marítima, eólica, hidráulica, solar e biomassa.

\section{Fundamentação teórica}

\section{Energia eólica}

Em um contexto nacional, a disposição de produção de energia eólica é uma das fontes renováveis de energia mais vastamente usufruída. Atualmente, existem muitos parques eólicos produzindo eletricidade. A energia eólica é uma fonte indireta de energia solar, no qual os ventos são causados pelo aquecimento desigual da superfície da Terra. Este aquecimento diferenciado de diversas regiões, especialmente da atmosfera, promove gradientes de pressão responsáveis pelo movimento de massas de ar. Além da diferença de pressão, o vento também sofre influência física das montanhas e outros possíveis obstáculos (Lu et al., 2009; Picolo et al., 2014).

Hoje, o uso da energia eólica utiliza turbinas de vários tamanhos e tipos para a conversão da energia dos ventos em elétrica, o que abre uma gama de diferentes desempenhos econômicos. A tecnologia de turbinas eólicas utilizada atualmente tem apenas algumas décadas e grande parte destas turbinas produzidas industrialmente são do tipo de eixo horizontal e a pluralidade delas tem rotores de três pás. Entretanto, nos últimos anos, estas máquinas também têm sido produzidas com duas pás, com o intuito de reduzir custos e prolongar sua vida útil, tornando-as mais leves e flexíveis, reduzindo assim a parcela de componentes de alta tecnologia (Marques, 2004; Tolmasquim, 2016).

A localização dos parques eólicos é de grande importância, pois a geração de energia eólica tende a ser dividida em dois tipos de instalações: onshore (em terra) e offshore (em alto mar). As instalações offshore são tendências de países com menor extensão territorial e menos espaço disponível para parques eólicos terrestres. Já as instalações onshore são geralmente divididas em duas subcategorias: centralizadas, com a utilização de grandes turbinas; e descentralizadas, que podem atender a demandas locais (Tolmasquim, 2016). 
Em nível global, a energia eólica contribuiu mais para o crescimento da geração renovável, até mais do que a solar, representando cerca de $50 \%$ da geração de energia renovável nos últimos anos (BP, 2019).

\section{Energia hidráulica}

A energia hidráulica é a principal fonte de geração de energia elétrica no sistema de energia brasileiro. Não foi apenas devido à sua competitividade econômica, mas também pelo fato de que seus recursos de energia em nível nacional são significativamente abundantes. Esta é uma tecnologia confiável e madura que possui a vantagem adicional de ser uma fonte de energia renovável (Queiroz et al., 2013).

A energia hidráulica é proveniente da energia potencial gravitacional e da irradiação solar. A energia solar e a gravidade regulam a evaporação, condensação e precipitação da água na superfície da terra. A diferença de altura entre volumes de água (declínio), que é proporcionado pelos relevos da superfície da terra, fornece um grande potencial energético que pode ser aproveitado pelas usinas hidrelétricas (Bermann, 2008).

A hidrelétrica é composta basicamente por uma barragem e um sistema de coleta, bem como por um sistema de adução de água, vertedouros e casa de força. A energia hidráulica atualmente é a segunda maior fonte de energia (primária) renovável no mundo (2\%), perdendo apenas para biocombustíveis (10\%). Apesar de representar um alto percentual na matriz energética brasileira, ela não é tão relevante no cenário mundial devido à sazonalidade (IEA, 2019).

\section{Biomassa}

Mesmo antes do surgimento da espécie humana, a biomassa era usada como fonte de energia. Estudos arqueológicos mostraram que hominídeos usavam o fogo há mais de um milhão de anos. No entanto, o uso desta fonte de energia se tornou regular cerca de 350.000 anos atrás. Foi essencial para a evolução humana o aproveitamento da energia da biomassa. Juntamente com esta evolução, seu próprio meio de obtenção e uso também progrediram, desde coletar lenha para cozinhar, proteger e aquecer, até práticas mais modernas de produção agrícola e industrial, como a utilização de biocombustíveis para gerar calor, eletricidade e força motriz (Goldemberg, 2009).

No comparativo da totalidade entre as fontes, a biomassa representou cerca de $30 \%$ da produção de energia primária entre os anos de 2010 e 2019 no Brasil (oferta total de energia considerando todas as suas aplicações ou utilizações) (EPE, 2020). Entretanto esta situação não ocorreu no ano de 1850, pois naquele momento a biomassa representava $85 \%$ do consumo mundial de energia, sendo, praticamente, o único meio de gerar energia usado pelo homem, além da força dos ventos para navegação, animais domesticados na agricultura e focos de carvão para aquecimento (Leite e Leal, 2007; Goldemberg, 2009).

Dentre as diferentes rotas de utilização da biomassa, a que tem maior impacto econômico para o nosso país é a produção de etanol por meio da cana de açúcar, derivando seu produto em etanol e bagaço, dois tipos de insumos fortes em algumas regiões do país (Silva e Campos, 2013; Goldemberg, 2017).

Porém, nas últimas décadas, os setores sucroenergético e de papel e celulose, tendo como fonte a lixívia, têm se expandido e suas unidades se modernizado. As unidades mais modernas trabalham com mais eficiência na cogeração e na utilização de energia por meio de processos industriais, resultando em maior excedente de bioeletricidade, aumentando assim a renda. Em consequência, a bioeletricidade começou a ter uma maior participação na oferta de energia interna no Brasil. Além disso, a lenha de florestas plantadas também tem sido bastante utilizada, contribuindo para a geração elétrica (Leite e Leal, 2007; Tolmasquim, 2016). 


\section{Energia solar}

A energia solar é uma energia livre, de fácil acesso, de utilização ilimitada e não excludente. A energia solar é tão abundante que, se fosse possível aproveitar toda a energia que chega à superfície da Terra, seria possível suprir toda a demanda energética humana por um ano com 75 min de captação (Micha et al., 2018).

Esta forma de energia pode ser utilizada de duas maneiras, a térmica e a fotovoltaica. Na térmica, sua utilização ocorre de modo mais simples e principalmente em domicílios. Seu desempenho é baixo, mas promove um aproveitamento de baixa, média e alta temperatura. Já o outro meio de energia renovável solar é a fotovoltaica, no qual a captação utiliza materiais semicondutores, que possuem efeito fotovoltaico e a energia é obtida por meio da conversão da radiação solar em eletricidade (Vichi e Mansor, 2009).

A célula solar fotovoltaica é o elemento principal nesta forma de obtenção de energia. Geralmente elas são feitas de silício e são montadas em série, de 28 a 216 células, formando assim os módulos fotovoltaicos. Estes módulos podem ser utilizados de forma individual, em série ou em paralelo. 0 ângulo de inclinação destes módulos se dará de acordo com a latitude da região (Brito e Silva, 2006).

A conversão de luz em energia ocorre quando as partículas de luz solar entram em contato com os átomos presentes nas células, gerando assim uma movimentação dos elétrons que irá resultar na formação da corrente elétrica. Se o sistema fotovoltaico em questão estiver conectado à rede, a corrente elétrica gerada será repassada para um inversor, que tem a função de transformar a corrente contínua em corrente alternada. Em sistemas fotovoltaicos isolados, energia adquirida pode ser armazenada em baterias ou seu excedente pode ser injetado na rede, gerando créditos ao produtor (Machado e Miranda, 2015).

Em um contexto de produção de energia solar fotovoltaica, o Brasil se encontra em uma posição geográfica privilegiada, recebendo diariamente grandes níveis de radiação solar, sua concentração varia entre 4,8 e $6,0 \mathrm{kWh} \cdot \mathrm{m}^{-2} \cdot \mathrm{dia}^{-1}$ (Bermann, 2008). Apesar dos fatores climáticos serem muito atrativos no país, a intermitência de radiação e a taxa de desempenho médio de conversão de energia de uma célula fotovoltaica, que está em torno de 15\%, trazem desafios de expansão (Micha et al., 2018).

\section{Energia marítima}

O Brasil possui uma grande disponibilidade de energia renovável como a solar, eólica e hidráulica. Entretanto, uma fonte muito abundante e pouco repercutida nacionalmente é a energia marítima, uma fonte renovável, não poluente e inesgotável (Kalogirou, 2014).

Historicamente, este método de energia iniciou-se na Europa, em meados do século XII, para a utilização de um moinho submarino. A força e o fluxo do mar promoviam a movimentação das pedras, moendo o que estava entre elas. Um método muito primitivo, entretanto, foi o necessário para começar a imaginar a energia proveniente do mar. 0 mar possui uma vasta quantidade de energia derivada do deslocamento de suas massas de água, constituindo uma grande fonte de energia para o mundo todo, sendo uma fonte energia que não agride o meio ambiente de forma significativa. 0 mar proporciona diferentes formas de energia marítima, porém regularmente disponíveis distantes dos locais de consumação. Estima-se que $0,02 \%$ da energia contida no oceano seria suficiente para atender a corrente demanda mundial por eletricidade (Amundarain et al., 2010).

Por mais que a energia marítima seja valiosa, ainda é pouco explorada. Neste momento, as usinas de geração de energia marítima não são abundantes e a maioria é de pequena escala, impossibilitando uma vasta utilização e exploração (Edenhofer et al., 2011).

A energia marítima possui muitas vantagens, mas em alguns quesitos torna-se inviável, quando comparadas com outras fontes renováveis de energia. A grande maioria 
dos sistemas marítimos de energia renovável utiliza tecnologias já existentes e comercialmente disponíveis, tais como os impulsores, cilindros hidráulicos e turbinas hidrelétricas de baixa pressão. A fonte de energia marítima consegue ser superior à energia solar e à eólica porque as ondas e correntes no fundo do mar podem manter suas características em uma longa distância, sendo possível prever as condições do mar com facilidade e precisão com mais de $48 \mathrm{~h}$ de antecedência (Leite Neto et al., 2011; Tolmasquim, 2016).

Deste modo, para que ocorra a efetivação da energia marítima, é possível extraí-la utilizando três tecnologias, a energia obtida através do movimento das ondas, a energia das variações de marés, que possui o mesmo princípio das hidrelétricas, e a energia cinética, através das correntes marítimas, semelhante à obtenção de energia eólica (Tolmasquim, 2016).

Apesar de ser uma fonte com alta capacidade de geração de energia, existem poucos projetos de geração devido ao custo de implantação elevado. A maior parte da geração é proveniente da energia das marés e está concentrada na França e Coreia do Sul, com geração de 240 e $250 \mathrm{MW}$, respectivamente. No entanto, com o desenvolvimento de novas tecnologias e/ou a escassez de energia de outras fontes, ela tem potencial para se tornar relevante na matriz energética mundial (Tolmasquim, 2016; Leite Neto et al., 2011).

\section{Panorama nacional e perspectivas futuras}

Com todo o crescimento populacional, constante avanço da urbanização e avanço tecnológico, a demanda de energia tem se tornado cada vez maior e a capacidade de geração no Brasil cada vez mais diversa. As fontes não renováveis de energia são poluentes e finitas, o que torna necessário a busca por fontes alternativas, as quais podem atender a demanda de energia de uma maneira sustentável e sem causar grandes impactos ambientais.

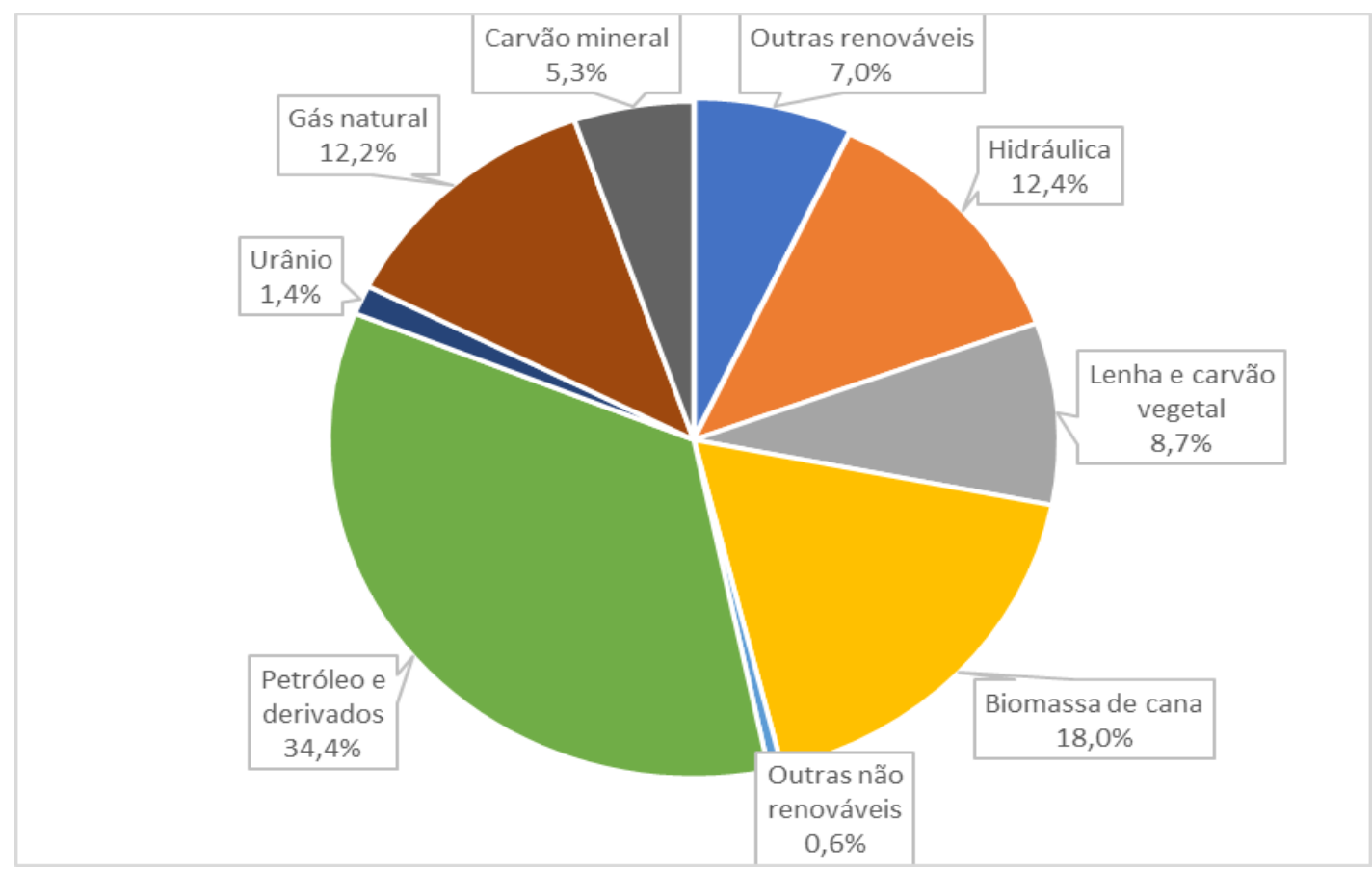

Figura 1. Distribuição de fontes de energia na matriz energética brasileira (oferta primária). Fonte: EPE (2020). 
No Brasil, segundo o Balanço Energético Nacional de 2020, a oferta primária de energia (Figura 1) possui maior participação de fontes fósseis $(53,9 \%)$ do que fontes renováveis $(46,1 \%)$, mesmo após todo o crescimento das fontes renováveis (EPE 2020, p. 14).

Uma característica marcante no Brasil é o fato da matriz energética ter uma ampla diversidade de fontes, o que acaba sobressaindo-se ao ser comparado em nível mundial, que apresentou um percentual de apenas 13,9\% de renováveis em 2017 (IEA, 2019). Das fontes renováveis de energia que mais se destacaram nos últimos anos, é preciso chamar atenção para a geração de eletricidade por meio da biomassa proveniente do bagaço da cana-de-açúcar e da fonte eólica. Segundo o Balanço Energético Nacional (2020), a fonte eólica teve um aumento de 15,5\% na produção de eletricidade de 2018 para 2019. Já a biomassa, em 2019, teve um aumento na fabricação de etanol de 5,9\%. Deve-se destacar também a energia solar fotovoltaica que cresceu pouco em 2019, mas se expandiu muito nos últimos anos (EPE, 2019). Já a fonte hidráulica teve uma leve queda percentual devido ao crescimento das outras fontes e impacto da sazonalidade.

0 fato do Brasil possuir quase $50 \%$ da matriz proveniente de fontes renováveis afeta diretamente as emissões de gases poluentes. Em relação às emissões na produção de energia, o total de emissões antrópicas associadas à matriz energética brasileira atingiu cerca de 419,9 milhões de toneladas de dióxido de Carbono equivalente, sendo a maior parte gerada no setor de transporte. Porém, ao considerar a emissão por habitante em 2019 através da produção e consumo de energia, o brasileiro emitiu 12,6 vezes menos do que um americano e aproximadamente quatro vezes menos do que um europeu ou chinês. Portanto, o setor elétrico brasileiro emitiu um índice muito baixo de dióxido de carbono quando se estabelece comparações com países da União Europeia, EUA e China (BEN, 2020).

Como as soluções de oferta de fontes renováveis de energia estão, na sua maior parte, relacionadas com a produção de energia elétrica, a partir deste momento será dado o enfoque no padrão de consumo e perspectivas de produção de energia elétrica. Além disso, a diminuição de combustíveis fósseis na matriz energética, ou seja, na sua oferta primária, pode ser melhorada com a oferta de energia elétrica de fonte renovável, visto que o Brasil possui grande utilização de combustíveis fósseis que podem ser resolvidos (ou parcialmente) com a utilização de veículos elétricos, o que está muito relacionado com as perspectivas futuras (Vasconcelos, 2017).

De acordo com o plano decenal de expansão de energia do Brasil para 2029, aproximadamente $50 \%$ da expansão contratada de energia elétrica será de fontes renováveis, com destaque para o crescimento das fontes eólica e solar. Um dado que chama atenção refere-se à expansão contratada de energia de fonte térmica, que corresponde à maior parcela de crescimento. No entanto, as usinas termelétricas exercem papel estratégico na segurança de operação, pois possuem previsibilidade de produção e complementam a matriz energética. Ademais, conforme descrito no plano de expansão ótimo, ocorrerá a saída de $15.500 \mathrm{MW}$ para a entrada de 27.800 MW de termelétricas de diversas tecnologias, sendo elas de melhores eficiências e vidas úteis (MME/EPE, 2019).

As participações das fontes no plano de expansão de oferta de energia elétrica estão representadas nas Figuras 2 e 3 . Os maiores crescimentos ocorrerão para termelétricas, eólica e solar, enquanto a implementação de hidrelétricas tende a diminuir. Apesar da diminuição percentual de hidrelétricas e aumento da capacidade de termelétricas, a participação de fontes renováveis na geração de energia elétrica ainda ficará acima de 80\%, mantendo a predominância de fontes não emissoras de gases do efeito estufa (MME/EPE, 2019).

Tratando agora de perspectivas de longo prazo, verifica-se que o território brasileiro ainda não possui um parque eólico offshore. Porém já existem cerca de três projetos com solicitação de licença ambiental. O mais promissor deles é o "EOL Planta 
Piloto de Geração Eólica Offshore (5 MW)", uma vez que se trata de um projeto de pesquisa, que vai ser localizado na Costa de Guamaré, no Rio Grande do Norte, onde a lâmina d'água mede entre $12 \mathrm{~m}$ e $16 \mathrm{~m}$. Segundo pesquisas da EPE, o Brasil tem um potencial eólico de $700 \mathrm{GW}$ em alto mar. Os outros projetos não têm previsão de serem instalados nos próximos anos. Questões ligadas ao licenciamento ambiental, modelo de concessão e implementação continuam sem respostas e são essenciais para o crescimento desta fonte de energia no país (MME/EPE, 2018).

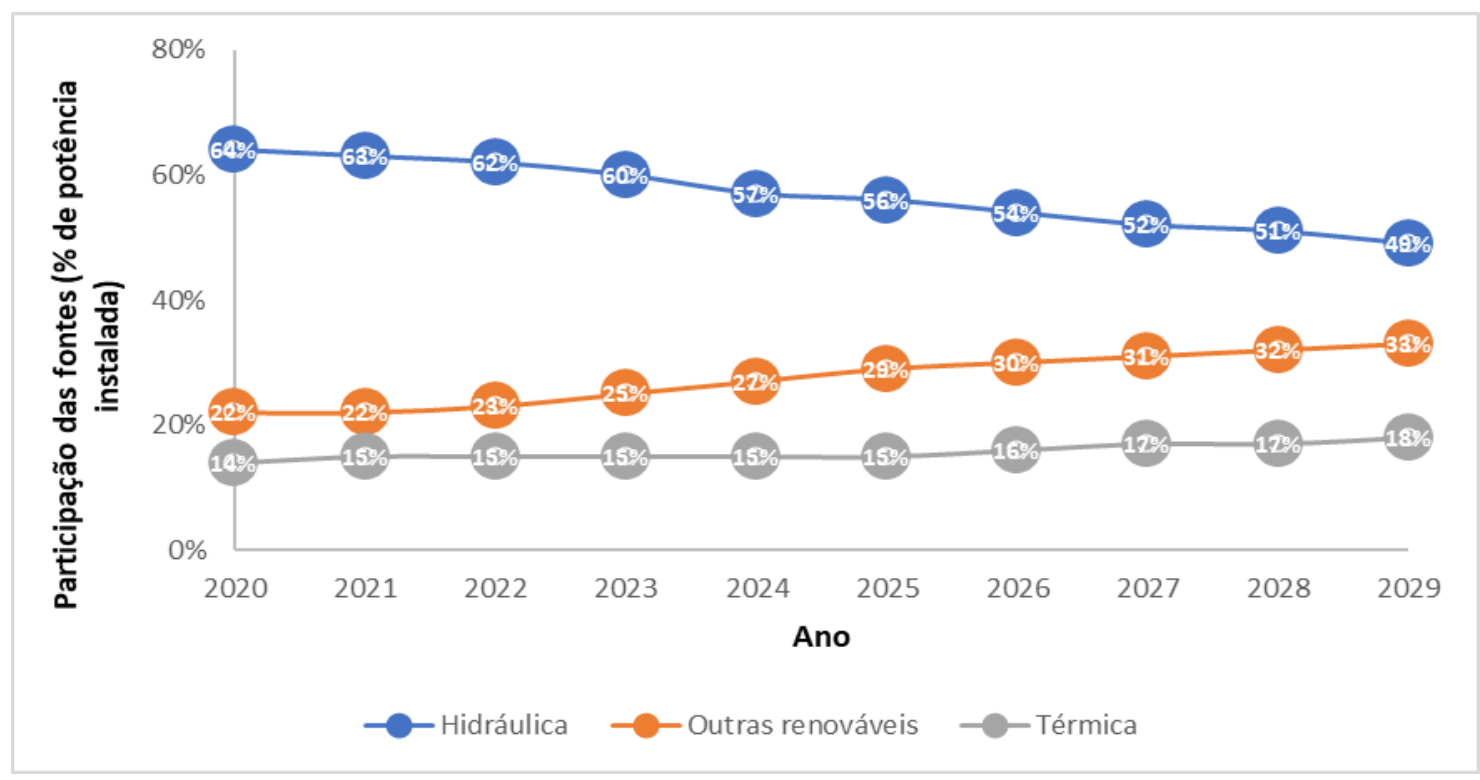

Figura 2. Participação das fontes no plano de expansão de oferta de energia elétrica. Fonte: MME/EPE (2019).

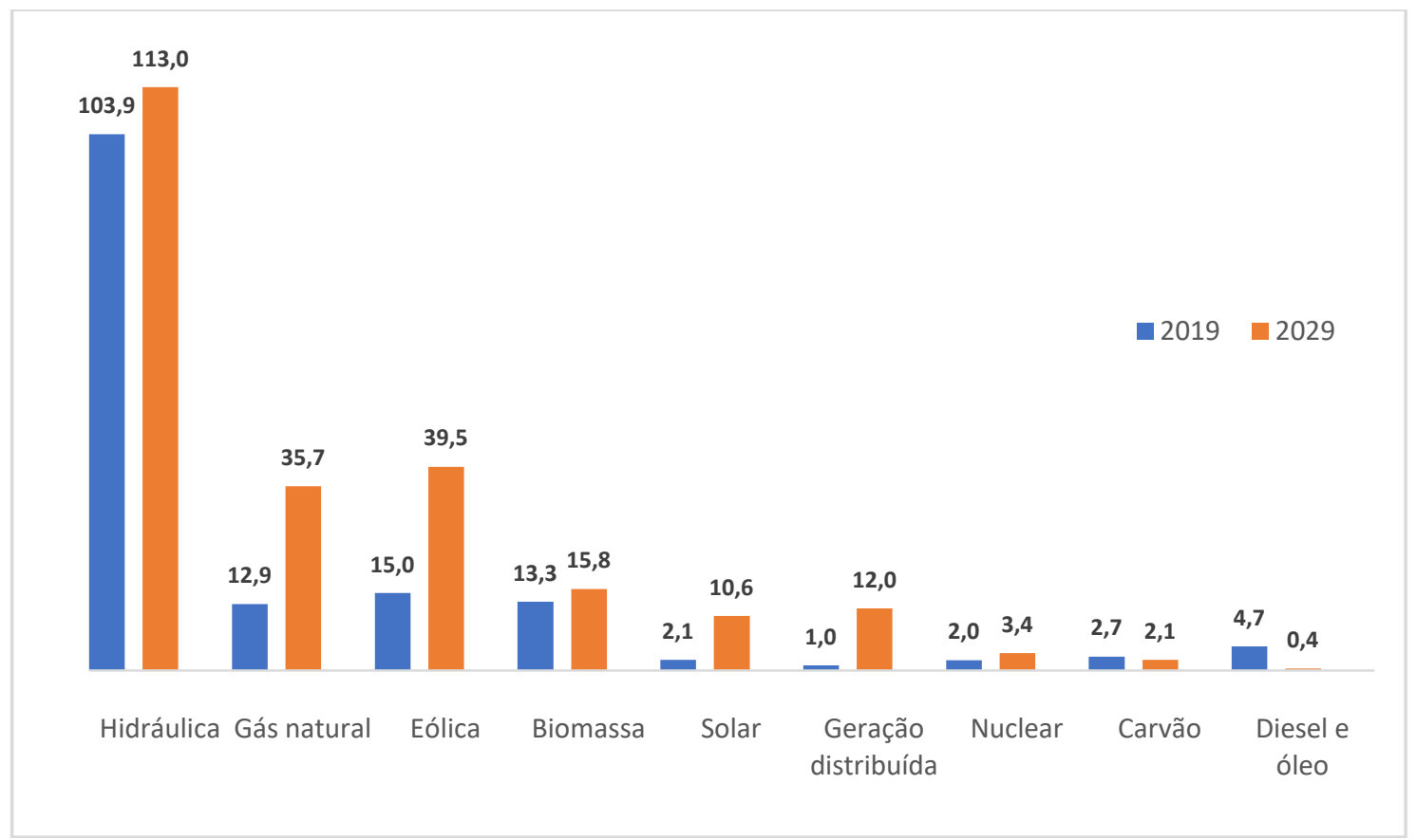

Figura 3. Expansão indicativa de referência e comparação de capacidade instalada em 2019 e 2029 (GW). Adaptado de MME/EPE (2019). 
Já se tratando de parques eólicos onshore, sabe-se que o Brasil tem aumentado a cada ano o seu potencial. Estima-se que ao longo dos próximos anos mais parques eólicos sejam criados e sua infraestrutura aprimorada (GWEC, 2018).

0 setor de energia tem enfrentado grandes desafios em relação a expansão da energia hidrelétrica, principalmente devido a questões socioambientais, uma vez que o potencial remanescente se localiza em áreas mais sensíveis. Esta sensibilidade acaba por refletir diretamente nos conflitos sociais, nas políticas de proteção e nas discussões sobre a implementação de usinas hidrelétricas (MME/EPE, 2018).

Diante disso, o governo, com o objetivo de estabelecer estratégias que possam conciliar a geração de energia e a conservação do meio ambiente, iniciou vários estudos estruturados e discussões acerca do tema. Outro projeto em andamento é a realização de estudos que estão voltados para o desenvolvimento sustentável das áreas onde podem ter usinas implantadas. Estas discussões são de extrema importância, uma vez que o Brasil pretende investir nesta fonte de energia abundante em nosso território (MME/EPE, 2015). Como dito anteriormente, esta fonte de energia terá uma contribuição menor ao longo dos anos, muito por necessidade de diversificação da matriz energética. Cabe destacar que o Brasil já enfrentou crises energéticas em 2001 e 2014 devido à concentração nesta fonte, que depende de fatores climáticos. Portanto, esta diminuição possui efeitos positivos no longo prazo (Tolmasquim, 2000).

o maior exemplo da importância da bioenergia no Brasil é o segmento sucroalcooleiro. O desenvolvimento do etanol e dos veículos com a nova tecnologia de combustível flex (misturas de gasolina e álcool) possibilitaram instalações de indústrias que serão capazes de atender às necessidades por novos projetos de unidades para a expansão desta fonte. Estima-se que até 2050 a produção da cana-de-açúcar chegue a crescer $55 \%$, ou seja, a aproximadamente um bilhão de toneladas. Já a produção energética de produtos da cana-de-açúcar pode chegar a 145 milhões de tonelada equivalente de petróleo (tep), um aumento de $67 \%$ se comparado ao ano de 2015 , onde se tinha 87 milhões de tep (Leite e Leal, 2007; MME/EPE, 2018).

Nos últimos anos, foram feitas análises espaciais para descobrir as localidades propícias para a instalação de futuras centrais fotovoltaicas. Em relação a estas áreas, foi decidido que seria realizado levantamentos de potencial em áreas antropizadas, desconsiderando as áreas que contém vegetação nativa. Feita esta análise, onde foi considerado apenas a melhor faixa de irradiação $\left(6,0\right.$ a $\left.6,2 \mathrm{kWh} / \mathrm{m}^{2}\right)$, foi estimado a possibilidade de instalação de $307 \mathrm{GWp}$ com uma geração de aproximadamente $506 \mathrm{TWh} /$ ano. Cabe reforçar que quase todo o território nacional é propício para o aproveitamento solar. Assim, estima-se que até 2050 seja possível a dispersão da energia fotovoltaica em todo o país (MME/EPE, 2018). No Brasil, há um interesse na área do semiárido nordestino brasileiro, pois não há fontes hídricas ou de biomassa abundantes. Entretanto, estas aplicações devem ser estendidas a outras regiões com o objetivo de diversificação da matriz energética (Bermann, 2008).

A extensa área costeira é a maior vantagem do Brasil para dar abertura para o aproveitamento energético dos recursos do mar. Os lugares mais propícios para o aproveitamento das correntes são nas regiões litorâneas do Norte e Nordeste, uma vez que a variação da maré é constante (MME/EPE, 2018). Dezenas de baías e estuários foram identificados nos Estados do Pará, Maranhão e Amapá, incluindo regiões fluviais, que recebem influência diária da maré em aproximadamente $800 \mathrm{~km}$. Foi considerado uma potência de $27 \mathrm{GW}$ nestas regiões, porém, estimativas apontam um aumento no potencial para $300 \mathrm{GW}$ até 2050 (OES, 2017; MME/EPE, 2018). 


\section{Aspectos relevantes de implantação}

A energia de fontes renováveis é obtida de bens naturais, como água, sol, ar e vegetação, que estão à disposição da humanidade. Assim, um bom planejamento pode aumentar o percentual de renováveis na matriz energética. No entanto, possíveis impactos ambientais, sociais e o custo de implantação provocam obstáculos em usufruir destes bens (Pedrosa, 2005).

Os aspectos econômicos mostram-se o maior cofator para o desenvolvimento destes novos recursos. Atualmente o Brasil possui uma grande parcela de energia proveniente de fonte hídrica, que possui um custo-benefício atrativo, mas apresenta inúmeros impactos socioambientais. Nesta perspectiva, todos os frutos tecnológicos disponíveis e em pesquisa se mostram importantes para o desenvolvimento sustentável de energia renovável (Tolmasquim, 2016). Deste modo, a projeção de crescimento deve ser aplicada na redução de poluição causada pelas fontes de energia convencionais e ser fonte de benefício a população em todos os níveis sociais e econômicos, tanto no meio rural quanto urbano. Novos projetos devem incluir zonas que se mostram prejudicadas não só pela localização, mas por sua condição. A tecnologia utilizada deve dar prioridade a materiais com conhecimento de produção em larga escala no Brasil, o que ajudará a reduzir o valor dos sistemas e desenvolver tecnologia nacional (ANEEL, 2008).

Analisando os impactos ambientais e sociais que estas fontes renováveis de energia provocam, é irrefutável que estes podem ser significativos. Nesta perspectiva, o Brasil vem buscando evitar consequências rigorosas em relação aos impactos ambientais produzidos pela energia de fontes não renováveis (Goldemberg e Lucon, 2007).

0 mundo está em uma corrida contra o tempo para efetivar a energia renovável como fonte de maior porcentagem, entretanto este processo é lento e requer investimento. Esta inquietação para com a energia não renovável tem relação aos seus impactos ambientais causados pelo constante crescimento da utilização de energia em todo o mundo. Isso acaba acarretando um amplo desafio, a produção de mais energia e que emita menos gases de efeito estufa (Goldemberg e Lucon, 2007).

Não dá para contestar que o aproveitamento da energia provoca impactos ao meio ambiente, consistindo em renovável ou não renovável, de modo que seja de pequena ou de grandes proporções. Entretanto, se houver um bom planejamento, os impactos possuem capacidade de serem minimizados através de um bom programa de recursos integrados, no qual busque promover um mundo mais sustentável por meio de medidas políticas e econômicas.

Dentro desta ótica, os efeitos de anos e anos de um modelo de consumo sobre o mau emprego dos recursos naturais, levou o Brasil a atingir um estágio muito preocupante, principalmente nas últimas décadas. Os reflexos das alterações climáticas estão se dando de modo desastroso. Sendo assim, torna-se mais recorrente a ocorrência de desastres naturais, além do impacto direto na atividade econômica, sobre regiões inteiras (ANEEL, 2008).

Há um estudo efetivado pela US Nacional Oceanic and Atmospheric Administration, que preocupa a população mundial. Com a utilização desacerbada de produtos que geram o aquecimento global, estimativas mostram que, no verão de 2037, toda a capa de gelo do Oceano Ártico poderá derreter (ANEEL, 2008). E para que isso não tenha efetividade em sua realização, é preciso mudar as origens dos problemas.

Como pode ser observado na Figura 4, a oferta de energia no Brasil modificou-se um pouco ao longo dos últimos anos, sendo majoritária de fontes não renováveis e poluentes. A maior oferta existente no Brasil é de longe a de petróleo, no qual a capacidade da sua produção é quatro vezes maior do que a produção de qualquer outra fonte de energia renovável (EPE, 2020). 


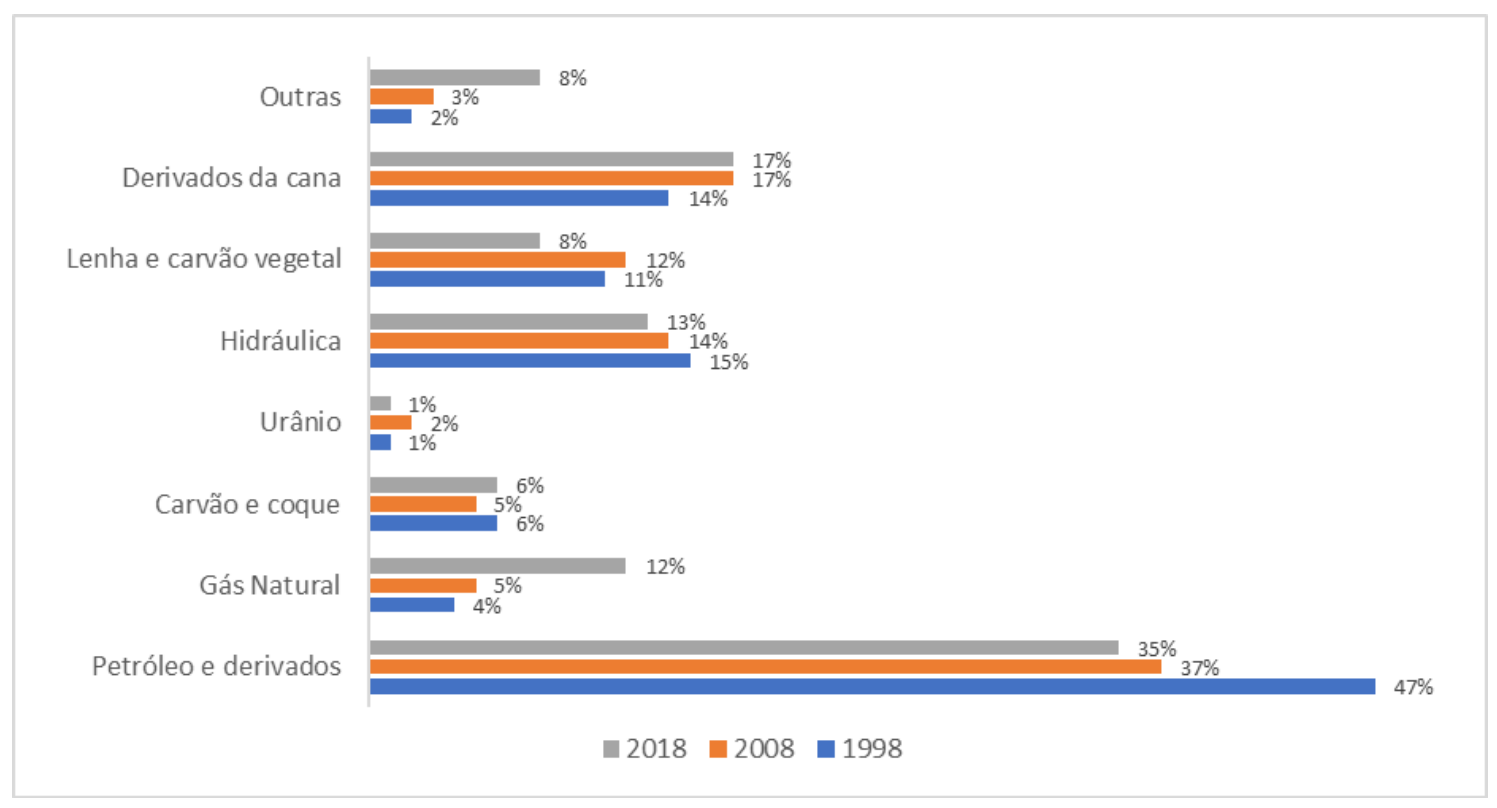

Figura 4. Evolução da oferta de energia primária no Brasil. Fonte: EPE (2020).

Se a utilização de fontes energéticas mais limpas não for uma política aplicada no mundo, haverá mudanças radicais derivadas do aquecimento global. Isto ocorrerá devido as sucessivas agressões ao ecossistema sem controle por muitos anos, pois sempre houve a priorização do desenvolvimento econômico. Portanto, se este círculo vicioso não se modificar, o mundo terá prejuízos econômicos cada vez maiores (Goldemberg e Lucon, 2007).

Há dois tipos de pensamentos que precisam ser modificados dentro desta perspectiva ambiental. 0 primeiro, pauta-se no crescimento e aceleração da economia, o outro, corresponde ao excesso de zelo pelo ecossistema. Sendo assim, é necessário encontrar um meio termo entre estas duas perspectivas, estabelecendo que os recursos naturais devem ser explorados de modo que permitam o incremento econômico sem a destruição do meio ambiente (Tolmasquim, 2016).

A vinda do Protocolo de Kyoto, um acordo mundial, foi benéfica para a humanidade, pois com sua implementação estipulou-se metas para a redução das emissões de gases poluentes e meios de compensação. Para países mais comprometidos com a preservação do meio ambiente, tem como efeito compensatório créditos de carbono. No entanto, os países têm encontrado dificuldades em cumprir com as metas estabelecidas desde a sua implantação (Tolmasquim, 2016).

Entre as formas de conversão conhecidas hoje para geração de energia, nenhuma é completamente limpa. 0 objetivo da pesquisa foi explorar fontes que causem o mínimo impacto ao meio ambiente. Com este ponto de vista, buscou-se um ótimo equilíbrio entre o custo de produção, demanda e impacto ambiental. A composição da matriz elétrica do Brasil tem maior contribuição de fonte hidráulica. No que diz respeito a impactos ambientais, as principais características estão relacionadas à inundação de grandes áreas e aos impactos na fauna e flora da região. Além disso, existe o assoreamento no leito dos rios, alteração no fluxo de corrente do rio, impactos climáticos na região (alteração da umidade, temperatura, evaporação, ventos e precipitação), entre muitos outros. Já considerando os impactos sociais temos o deslocamento de comunidades e extinção de diversas propriedades rurais. Levando tudo isso em conta, o impacto no meio ambiente é crucial. 
Com relação à energia marítima, os impactos ao meio ambiente são parecidos com os da hidráulica, em relação à fauna e à flora. A oxidação de seus componentes que ficam em alto mar pode acabar por modificar o ecossistema da área. Porém estes impactos são em escalas bem menores (Goldemberg e Lucon, 2007).

A produção de etanol por meio da biomassa é uma fonte que contribui para a poluição atmosférica, do solo e dos recursos hídricos, pois durante a cogeração de energia acaba por produzir muitos resíduos e gases poluentes. Mesmo assim, são em escalas muito menores em comparação com a energia de origem fóssil por serem renováveis.

Entre as fontes de energia mais limpas, a energia eólica e solar são as que menos impactam o meio ambiente e mais tem crescido no Brasil. A principal crítica que a eólica recebe é sobre a poluição sonora e visual que ela gera e, por isso, que os parques eólicos são majoritariamente implantados longe dos centros urbanos. $\mathrm{Na}$ energia solar os impactos ambientais estão associados à retirada ou soterramento da vegetação na área de implantação e no processo produtivo de suas placas (Goldemberg e Lucon, 2007).

o Brasil obtém uma vasta capacidade para gerar energia a partir das fontes descritas e detém potencial de geração maior quando comparado com muitos países pelo mundo. Contudo, ao referir-se a fontes renováveis, há uma grande problemática em torno de seus custos, pois o uso de tecnologias e implementações deparam-se ainda com certas dificuldades (Vichi e Mansor, 2009).

Determinadas dificuldades costumam ser iguais em todas as novas tecnologias de implantação, tanto nacionalmente como internacionalmente. Entre elas estão fracassos de mercado e barreiras econômicas e fiscais. Nas circunstâncias da energia renovável, são detectados problemas em suas barreiras econômicas como um mercado limitado junto a estas tecnologias, influenciando diretamente no custo destas fontes (Tabela 1) (Vichi e Mansor, 2009).

Tabela 1. Síntese de custos das fontes de energia. Adaptado de: MME/EPE, 2018.

\begin{tabular}{|l|c|c|c|}
\hline \multicolumn{1}{|c|}{ Fonte de geração } & $\begin{array}{c}\text { Custo de implementação } \\
\text { (US\$/kW) }\end{array}$ & $\begin{array}{c}\text { Custo de operação } \\
\text { anual (R\$/kW/ano) }\end{array}$ & $\begin{array}{c}\text { Custos Variáveis } \\
\text { (R\$/MWh) }\end{array}$ \\
\hline $\begin{array}{l}\text { Grandes e pequenas } \\
\text { centrais hidrelétricas }\end{array}$ & 1.800 a 4.800 & $26 / 100$ & - \\
\hline Fotovoltaica & 950 a 2.500 & $20 / 12$ & - \\
\hline Heliotérmica & 3.500 a 8.000 & $70 / 47$ & - \\
\hline É́lica onshore & 1.800 a 2.000 & 100 & - \\
\hline Eólica offshore & 2.500 a 5.000 & 210 & - \\
\hline Bagaço (cana) & 600 a 2.000 & 120 & 150 \\
\hline Floresta & 1.000 a 3.000 & 120 & 260 \\
\hline Gás natural & 700 a 1.200 & 170 & 400 \\
\hline Gás natural & 600 a 1.000 & 270 & 85 \\
\hline Carvão nacional & 1.900 a 2.800 & 100 & 140 \\
\hline Carvão importado & 800 a 3.000 & 100 & 25 \\
\hline Nuclear & 2.000 a 6.500 & 325 & - \\
\hline Hidrelétricas reversíveis & 1.000 a 2.000 & $60 / 100$ & - \\
\hline
\end{tabular}

Na energia eólica, há um valor médio sobre seu custo, nivelado aproximadamente entre US\$ $1.800 / \mathrm{kW}$ e US $\$ 2.000 / \mathrm{kW}$, para parques onshore, e entre US\$2.500/kW a US\$ $5.000 / \mathrm{kW}$, para parques offshore. Outra fonte de energia é a hidráulica, com valores de investimento com grande variabilidade, de início de US\$1.000/kW e máximo de US\$ $4.800 / \mathrm{kW}$. A energia solar não possui um investimento inicial muito alto, entre US\$ 
$950 / \mathrm{kW}$ e US\$ $2.500 / \mathrm{kW}$. Já a biomassa, possui variação de custo de investimento nos empreendimentos termelétricos e na indústria sucroalcooleira, entre US\$337/kW e US\$ $2.002 / \mathrm{kW}$. Esses valores oscilam de acordo com o uso da tecnologia e a operacionalidade do parque sucroalcooleiro brasileiro. Exemplo disso tem-se o etanol proveniente da cana-de-açúcar, que equivale como cotação sobre o combustível da palha a um valor de U\$ 19/t. Em uma boa safra este valor pode chegar a US\$22/MWh (MME/EPE, 2018).

Analisando os custos das fontes renováveis de energia vemos que, dentro da perspectiva de implantação e operação, a hidráulica não possui vantagens frente à eólica e solar. No entanto, quando avaliado sua importância no fornecimento contínuo de energia, a hidráulica torna-se mais relevante porque a eólica e solar possuem grande intermitência de produção. Ambas dependem de fatores naturais, causando grandes variações de potência ao longo do tempo. No caso da energia solar, podem ocorrer grandes variações dentro de um intervalo de tempo muito pequeno devido à presença de nuvens, além da ausência de produção no período noturno. Dentro deste contexto, a implantação de novos projetos de fontes solares e eólicas deve ser avaliada dentro das perspectivas de uma rede de transmissão integrada com fontes mais previsíveis (termelétricas, hidrelétricas, etc) e parques de produção dispersos, diminuindo os riscos de intermitência.

A geração de energia elétrica a partir de fontes de biomassa é importante no aproveitamento de subprodutos, como bagaço de cana de açúcar e lixívia, além de possuir custos de implantação e operação similares as demais fontes renováveis. No entanto, a produção de energia a partir de florestas é contestável devido a necessidade da utilização de grandes áreas de plantação, podendo causar danos ao solo e pressão sobre o preço de alimentos.

Diante do cenário nacional, as fontes de energia eólica e solar possuem maior potencial de crescimento por serem mais limpas e possuírem bom custo-benefício. No entanto, este crescimento não pode ocorrer na mesma proporção para a fonte hidráulica, mesmo sendo renovável, devido aos custos e os riscos, pois o Brasil possui alta dependência desta fonte, no qual foi palco de crises energéticas devido a esta alta concentração.

Apesar do alto potencial nacional para fontes renováveis, a expansão de fontes fósseis ocorrerá devido a maior previsibilidade de produção e complementação da matriz energética, fornecendo maior garantia em momentos de pico de uso de energia e baixa produção de fontes renováveis. Portanto, para que ocorra o emprego destas fontes renováveis (eólica e solar) é necessário que o governo mantenha incentivos, colaborando para diminuição dos custos e riscos relacionados aos investimentos em energia renovável (Vichi e Mansor, 2009; Pinto e Santos, 2019; Amato, 2020).

A energia marítima tem custo elevado, sendo o principal problema para a sua operacionalização. Em um contexto geral, possui custo de investimento inicial que varia entre US $\$ 4.500 / \mathrm{kW}$ e US $\$ 6.000 / \mathrm{kW}$ e, com as taxas, o valor final pode ser muito mais elevado. Além dos custos de implantações serem expressivos, o mercado brasileiro ainda não usufrui deste recurso, podendo assim, ocorrer falhas de mercado e barreiras econômicas (Piacentini, 2016). No entanto, esta fonte pode se tornar competitiva por meio de incentivos, sejam eles econômicos ou de investimento em pesquisa (Estefe, 2006; Vichi e Mansor, 2009).

As fontes renováveis de energia possuem muitos benefícios de implantações no longo prazo, mas, como o Brasil é um país de dimensão continental, os seus potenciais de implantações devem ser analisados por regiões. A Tabela 2 abaixo resume as vantagens e desvantagens de implantação das principais fontes renováveis de energia no país. Cabe destacar que as fontes renováveis demandam muitos incentivos, mas a longo prazo os efeitos de diminuição da poluição e diversificação matriz energética compensam este custo inicial. 
Tabela 2. Resumo de vantagens e desvantagens de implantação e operação de diferentes fontes renováveis de energia.

\begin{tabular}{|c|c|c|}
\hline $\begin{array}{l}\text { Fonte de } \\
\text { energia }\end{array}$ & Vantagens & Desvantagens \\
\hline Solar & $\begin{array}{ll}\text { - } & \text { Custo de implantação e operação } \\
\text { - } & \text { Grande potencial de geração } \\
\text { energética em sua longa vida útil, } \\
\text { de mais de } 20 \text { anos } \\
\text { - } \quad \text { Inesgotável } \\
\text { - } \quad \text { Ausência de resíduos e gases do } \\
\text { - } \quad \text { Coneito estufa durante a operação desenvolvimento de } \\
\text { - } \quad \text { Impornologia e redução de custos } \\
\text { - } \quad \text { matriz energética } \\
\text { Baixo tempo de implantação }\end{array}$ & $\begin{array}{l}\text { - } \quad \text { Não gera energia durante período } \\
\text { noturno } \\
\text { - } \quad \text { Alguns locais não são viáveis a } \\
\text { utilização desta fonte de energia } \\
\text { - Intermitência na produção, } \\
\text { - } \quad \text { mesmo durante o dia } \\
\text { Depende de incentivos }\end{array}$ \\
\hline Eólica & 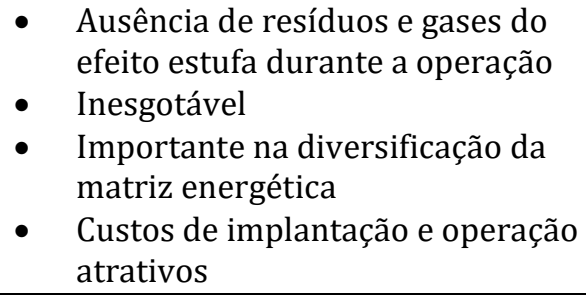 & $\begin{array}{ll}\text { - } & \text { Intermitência dos ventos } \\
\text { - } & \text { Impacto visual } \\
\text { - } & \text { Impacto sonoro } \\
\text { - } & \text { Impacto na vida de aves } \\
\text { - } & \text { Depende de incentivos } \\
\text { - } & \text { Logística de transporte complexa } \\
& \text { na implantação } \\
\end{array}$ \\
\hline Hidrelétrica & 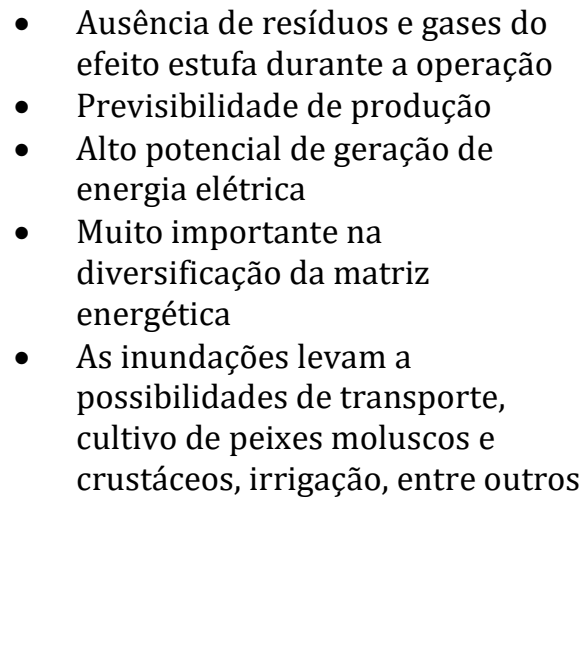 & $\begin{array}{l}\text { - } \quad \text { Depende das precipitações } \\
\text { - } \quad \text { Alto investimento inicial } \\
\text { - } \text { dos inundações para a formação } \\
\text { econômicos, sociais, ambientais e } \\
\text { culturais } \\
\text { - } \text { Alteração do fluxo de corrente do } \\
\text { rio } \\
\text { - Impactos climáticos, como a } \\
\text { alteração da umidade, } \\
\text { temperatura, evaporação, ventos e } \\
\text { precipitação } \\
\text { - } \text { Impactos na fauna e flora } \\
\text { Regiões de planícies necessitam de } \\
\text { uma inundação maior por unidade } \\
\text { de energia }\end{array}$ \\
\hline Biomassa & 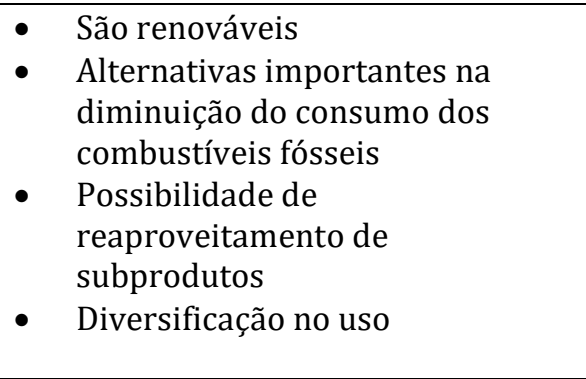 & 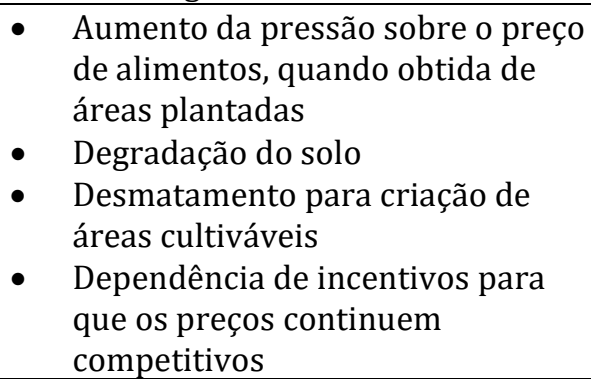 \\
\hline
\end{tabular}


Tabela 2. Continuação.

\begin{tabular}{|c|c|c|}
\hline $\begin{array}{l}\text { Fonte de } \\
\text { energia }\end{array}$ & Vantagens & Desvantagens \\
\hline Marítima & $\begin{array}{ll}\text { - } & \text { Inesgotável } \\
\text { - } & \text { Ausência de resíduos e gases do } \\
\text { efeito estufa durante a operação } \\
\text { - } \quad \text { Constância e previsibilidade de } \\
\text { produção }\end{array}$ & $\begin{array}{ll} & \text { Custo de implementação muito } \\
\text { - } & \text { Impactos no ecossistema marinho } \\
\text { - } & \text { Baixo aproveitamento energético } \\
\text { - } & \text { Depende do vento e das condições } \\
\text { do mar } \\
\text { - } \\
\text { Necessita de instalações mais } \\
\text { robustas para suportar os } \\
\text { impactos do mar e o ambiente } \\
\text { corrosivo }\end{array}$ \\
\hline
\end{tabular}

Fontes: Queiroz et al. (2013), Tolmasquim (2016), Goldemberg (2017), Micha et al. (2018), BP (2019).

\section{Considerações finais}

Através do levantamento obtido nesta pesquisa bibliográfica, pôde-se concluir que o Brasil possui grande potencial de produção de energia através de todas as fontes citadas. No entanto, por ser um país de dimensão continental, algumas regiões possuem características mais favoráveis para algumas delas, mostrando a importância do sistema interligado de energia e que será necessário investimento com a expansão prevista.

A composição da matriz energética no Brasil não obteve ganho percentual de renováveis em relação as não renováveis. Todavia, mesmo com o crescimento do consumo, foi observado uma estabilização, algo positivo quando comparado com a média global.

Tratando das perspectivas futuras de fontes renováveis, será observado um forte crescimento em solar e eólica, mas que possuem desvantagens devido às fortes intermitências de produção. A biomassa terá um baixo crescimento por já possuir um alto aproveitamento na oferta primária de energia através da produção de biocombustíveis e reaproveitamento de subprodutos. As hidrelétricas diminuirão em percentual de energia gerada devido à grande capacidade já instalada, barreiras econômicas e socioambientais. A energia marítima ainda não possui participação na matriz energética por ser inviável economicamente. No entanto, pesquisas científicas ocorrem no país para viabilizar a produção em larga escala.

\section{Agradecimentos}

Os autores agradecem ao Centro Federal de Educação Tecnológica Celso Suckow da Fonseca (CEFET-RJ).

\section{Conflito de interesses}

Os autores declaram não haver conflito de interesses.

\section{Referências}

Amato, F. Incentivo a fontes de energia vai custar R \$ 5,6 bilhões aos consumidores em 2020, diz Aneel. G1-Globo, 2020. Disponível em: <https://g1.globo.com/economia/ noticia/2020/01/26/incentivo-a-fontes-de-energia-vai-custar-r-56-bilhoes-aosconsumidores-em-2020-diz-aneel.ghtml>. Acesso em: 19 fev. 2021. 
Amundarain, M.; Alberdi, M.; Garrido, A. J.; Garrido, I.; Maseda, J. Wave energy plants: Control strategies for avoiding the stalling behaviour in the Wells turbine. Renewable Energy, v. 35, n. 12, p. 2639-2648, 2010. https://doi.org/10.1016/j.renene.2010.04.009

ANEEL - Agência Nacional de Energia Elétrica. Relatório ANEEL 10 anos. Brasília: ANEEL, 2008. Disponível em: <https://www.aneel.gov.br/documents/656835/14876457/ 2008_Relatorio10Anos/3e6e6e85-c2d9-98a3-d5fb-7646289abdf0>. Acesso em: 23 jan. 2021.

Bermann, C. Crise ambiental e as energias renováveis. Ciência e Cultura, v. 60, n. 3, p. 20-29, 2008.

BP. Statistical Review of World Energy. 68.ed. 2019. Disponível em: $<$ https://www.bp.com/content/dam/bp/business-sites/en/global/corporate/pdfs/ energy-economics/statistical-review/bp-stats-review-2019-full-report.pdf $>$. Acesso em: 22 jan. 2021.

Brito, M. C.; Silva, J. A. Energia fotovoltaica: conversão de energia solar em eletricidade. 0 instalador, 2006. Disponível em: <http://solar.fc.ul.pt/i1.pdf>. Acesso em: 20 dez. 2020.

Correa-Macana, E.; Comim, F. Mudança climática e desenvolvimento humano: uma análise baseada na abordagem das capacitações de Amartya Sen. Economia, Sociedad y Territorio, v. 8, n. 43, p. 577-618, 2012.

Edenhofer, O.; Madruga, R. P.; Sokona, Y.; Seyboth, K.; Matschoss, P.; Kadner, S.; Zwickel, T.; Eickemeier, P.; Hansen, G.; Schlömer, S.; Stechow, C. V. (Eds.). Renewable energy sources and climate change mitigation: Special report of the Intergovernmental Panel on Climate Change. New York: Cambridge University Press, 2011. Disponível em: <https://www.ipcc.ch/site/assets/uploads/2018/03/SRREN_Full_Report-1.pdf>. Acesso em: 23 jan. 2021.

Estefen, S.; Costa, P. R.; Pinheiro, M. M.; Ricarte, E.; Mendes, A.; Esperança, P. T. Geração de energia elétrica pelas ondas do mar. 2006. Disponível em: <https://www.coppe.ufrj.br/pt-br/geracao-de-energia-eletrica-pelas-ondas-do-mar-0>. Acesso em: 21 fev. 2021.

EPE - Empresa de Pesquisa Energética. Atlas de eficiência energética: Brasil/2019 relatório de indicadores. 2019. Disponível em: <https://www.epe.gov.br/sitespt/publicacoes-dados-abertos/publicacoes/PublicacoesArquivos/publicacao-461/Atlas da Eficência Energética do Brasil (002).pdf>. Acesso em: 19. nov. 2020.

EPE-Empresa de Pesquisa Energética. Balanço Energético Nacional 50 anos: cinquenta anos de estatísticas energéticas (BEN 50 ANOS). 2019. Disponível em: <https://www.epe.gov.br/sites-pt/publicacoes-dados-abertos/publicacoes/Documents/ BEN 50 anos.pdf>. Acesso em: 19 out. 2020.

EPE - Empresa de Pesquisa Energética. Balanço Energético Nacional (BEN) 2020: Ano base 2019, 2020. Disponível em <https://www.epe.gov.br/sites-pt/publicacoes-dadosabertos/publicacoes/PublicacoesArquivos/publicacao-479/topico528/BEN2020_sp.pdf>. Acesso em: 11 dez. 2020.

EPE - Empresa de Pesquisa Energética. Balanço Energético Nacional (BEN) 2020: Relatório Síntese/Ano base 2019. 2020. Disponível em: <https://www.epe.gov.br/sitespt/publicacoes-dados-abertos/publicacoes/PublicacoesArquivos/publicacao-479/topico521/Relatório Síntese BEN 2020-ab 2019_Final.pdf>. Acesso em: 11 dez. 2020.

Goldemberg, J.; Lucon, O. Energia e meio ambiente no Brasil. Estudos Avançados, v. 21, n. 59, p. 7-20, 2007. https://doi.org/10.1590/S0103-40142007000100003 
Goldemberg, J. Biomassa e energia. Quimica Nova, v. 32, n. 3, p. 582-587, 2009. https://doi.org/10.1590/S0100-40422009000300004

Goldemberg, J. Atualidade e perspectivas no uso de biomassa para geração de energia. Revista Virtual de Química, v. 9, n. 1, p. 15-28, 2017.

GWEC - Global Wind Energy Council. Global Wind Statistics 2017. 2018. Disponível em: <https://gwec.net/wp-content/uploads/vip/GWEC_PRstats2017_EN-003_FINAL.pdf>. Acesso em: 11 dez. 2020.

IEA - International Energy Agency. World energy balances overview. 2019 edition. Disponível em: <https://www.iea.org/publications/freepublications/>. Acesso em: 19 nov. 2020.

IPCC - Intergovernmental Panel on Climate Change. Climate change 2013: The physical science basis. Genebra: IPCC, 2013. Disponível em: <https://www.ipcc.ch/site/ assets/uploads/2018/03/WG1AR5_SummaryVolume_FINAL.pdf>. Acesso em: 12 jan. 2021.

Kalogirou, S. A. Engenharia de energia solar: processos e sistemas. 2. ed. Rio de Janeiro: Elsevier, 2016.

Leite Neto, P. B.; Saavedra, O. R.; Camelo, N. J.; Ribeiro, L. A. S.; Ferreira, R. M. Exploração de energia maremotriz para geração de eletricidade: aspectos básicos e principais tendências.

Ingeniare. Revista Chilenade Ingeniería, v. 19, $\quad$ n. 2, p. 219-232, 2011. https://doi.org/10.4067/S0718-33052011000200007

Leite, R. C. C.; Leal, M. R. L. V. O biocombustível no Brasil. Novos Estudos CEBRAP, n. 78, p. 15-21, 2007. https://doi.org/10.1590/S0101-33002007000200003

Lu, X.; McElroy, M. B.; Kiviluoma, J. Global potential for wind-generated eletricity. PNAS, v 106, n. 27, p. 10933-10938, 2009. https://doi.org/10.1073/pnas.0904101106

Machado, C. T.; Miranda, F. S. Energia solar fotovoltaica: uma breve revisão. Revista Virtual de Química, v. 7, n. 1, p. 126-143, 2015.

Marques, J. Turbinas eólicas: modelo, análise e controle do gerador de indução com dupla alimentação. Santa Maria: Universidade Federal de Santa Maria, 2004. (Dissertação de mestrado).

Micha, D. N.; Torres Junior, R.; Rocha, B. V.; Silva, D. A.; Almeida, L. B. O atual desafio energético-ambiental mundial e a energia solar fotovoltaica. Revista Tecnologia \& Cultura, v. 21, n. 31, p. 77-86, 2018.

MME/EPE - Ministério de Minas e Energia/Empresa de Pesquisa Energética. Plano Decenal de Expansão de Energia 2024. Rio de Janeiro: MME/EPE, 2015. Disponível em: <https://www.epe.gov.br/sites-pt/publicacoes-dados-abertos/publicacoes/Publicacoes Arquivos/publicacao-45/topico-79/Relatório Final do PDE 2024.pdf>. Acesso em: 26 out. 2020.

MME/EPE - Ministério de Minas e Energia/Empresa de Pesquisa Energética. Potencial de Recursos Energéticos no Horizonte 2050. Rio de Janeiro: MME/EPE, 2018. Disponível em: $\quad<$ https://www.epe.gov.br/sites-pt/publicacoes-dados-abertos/publicacoes/ PublicacoesArquivos/publicacao-227/topico-416/03. Potencial de Recursos Energéticos no Horizont 2050 (NT PR 04-18).pdf>. Acesso em: 26 out. 2020. 
MME/EPE - Ministério de Minas e Energia/Empresa de Pesquisa Energética. Plano Decenal de Expansão de Energia 2029. Rio de Janeiro: MME/EPE, 2019. Disponível em: <https://www.epe.gov.br/sites-pt/publicacoes-dados-abertos/publicacoes/Publicacoes Arquivos/publicacao-422/PDE 2029.pdf>. Acesso em: 22 jan. 2021.

Nascimento, T. C.; Mendonca, A. T. B. B.; Cunha, S. K. Inovação e sustentabilidade na produção de energia: o caso do sistema setorial de energia eólica no Brasil. Cadernos

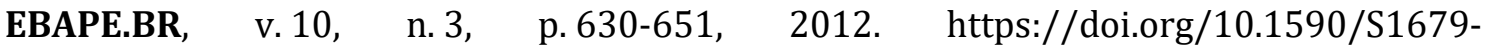
39512012000300010

OES - Ocean Energyu Systems. An international vision for ocean energy 2017. 2017. Disponível em: <https://testahemsidaz2.files.wordpress.com/2017/03/oes-internationalvision.pdf>. Acesso em: 11 nov. 2020.

Pedrosa, P. G. B. M. Desafios da regulação do setor elétrico, modicidade tarifária e atração de investimentos. Brasília: ANEEL, 2005.

Piacentini, P. Faltam estratégias no Brasil para gerar energia das marés. Ciência e Cultura, v. 68 , n. 3, p. 11-13, 2016.

Picolo, A. P.; Rühler, A. J.; Rampinelli, G. A. Uma abordagem sobre a energia eólica como alternativa de ensino de tópicos de física clássica. Revista Brasileira de Ensino de Física, v. 36, n. 4, p. 4306, 2014. https://doi.org/10.1590/S1806-11172014000400007

Pinto, R. J.; Santos, V. M. L. Energia eólica no Brasil: evolução, desafios e perspectivas. Journal on Innovation and Sustainability, v. 10, n. 1, p. 124-142, 2019.

Queiroz, R.; Grassi, P.; Lazzare, K.; Koppe, E.; Tartas, B. R.; Kemerich, P. D. C. Geração de energia elétrica através da energia hidráulica e seus impactos ambientais. REGET, v. 13, n. 13, p. 2774-2784, 2013. https://doi.org/10.5902/223611709124

Silva, W. A.; Campos, V. R. Etanol (CAS No. 64-17-5). Revista Virtual de Química, v. 5, n. 5, p. 1007-1021, 2013.

Tolmasquim, M. T. As origens da crise energética brasileira. Ambiente \& Sociedade, n. 6/7, p. 179-183, 2000. https://doi.org/10.1590/S1414-753X2000000100012

Tolmasquim, M. T. Energia renovável hidráulica, biomassa, eólica, solar e oceânica. 2. ed. rev. ampl. Rio de Janeiro: Empresa de Pesquisa Energética, 2016.

Vasconcelos, Y. A ascensão dos elétricos: automóveis movidos à eletricidade não deverão representar 16\% da frota mundial até 2030. Revista Pesquisa FAPESP, n. 258, p. 18-27, 2017.

Vichi, F. M.; Mansor, M. T. C. Energia, meio ambiente e economia: o Brasil no contexto mundial. Química Nova, v. 32, n. 3, p. 757-767, 2009. 